\section{TREATMENT OF MIDDLE-EAR SUPPURATION.*}

HASSAN BEY SHAHEEN, M.R.C.S., L.R.C.P., AURAL SURGEON, KASR-EL-AINI HOSPITAL.

Diseases of the middle ear, whether of the dry or suppurative type, tend to run a chronic course unless they are dealt with promptly and energetically. Adequate treatment can be ensured only if the patient is seen regularly; but in hospital practice, where patients are drawn from the working classes, one often finds that the patient's regular attendance can be secured only at the risk of his losing his work.

Dry conditions of the middle ear which have failed to derive benefit from catheterization and massage frequently respond to treatment by intravenous injection of colloid iodine; suppurative otitis media is, however, a far more serious and dangerous type of disease, and failure to treat it adequately has undoubtedly been responsible for a large number of operations on the temporal bone.

I have been able to cure many cases of chronic ear suppuration by the subcutaneous or intramuscular injection of milk boiled for three to ten minutes and injected at body beat: The treatment has two advantages: it is cheap, and it is within the province of the general practitioner. One injection is sometimes sufficient to stop discharge, though in cases with small granulations and a fetid discharge several injections may be necessary. The injections are often followed by severe gencral symptoms closely resembling those of an attack of influenza. Sometimes there are rigors, and vomiting may occur. Among patients observed under hospital conditions the reaction was found to begin within an hour or two of the injection, reaching its maximum in six to twelve hours, when often the temperature would rise to $103^{\circ}$ or $104^{\circ} \mathrm{F}$., and then return to normal in about twelve hoturs. Most of the effects passed off within twenty-four hours, but in view of the fact that there is sometimes pyrexia for two or three days, rest in bed should always be enforced.

When $I$ first instituted this treatment $I$ refrained from giving it to young children; with further experience I have been able to regulate the closage, so that children may now submit to the treatment without suffering unduly. Treatment is contraindicated in patients with cardiac or renal disease, and the risk of anaphylaxis must ahways be considered and guarded against. The following is a short outline of a few of the eases treated by this method.

Case 1.-A girl, aged 6, had suffered from fetid dischargt of the right ear for four years. She was given an reaction. Two days later the discharge stopped completely. After five days a further 2 c.em. were injected, again producing a general reaction. The condition appears to have cleared up and the ear is absolutely dry.

C'tsc 2.-A man, aged 20, was admitted to hospital on June 11th, 1928, with a fetid discharge from the right car, from which he had suffered for seven years. There was a posterior perforation, and small granulations were present; $5 \mathrm{c.cm}$. of milk were injected, and the temperature rose to $102^{\circ}$. On June 14th there was less discharge, but the fetor continued; $10 \mathrm{c.cm}$. were injected, and though there was again a general reaction, there was a diminution both in the amount of the discharge and in the fetor following. On June 20 th another 10 c.cm. were injected and improvement was sustained. After similar injections on June 24 th and July 1st, 4th, and 15 th, the patient had rather more

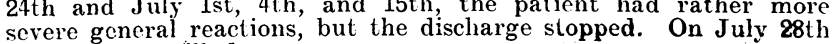
the ear was still dry.

C'use 3.-A male infant, aged 2, was brought to me with a post-operative sinus leading to the tympanic antrum, and with fetid discharge from the ear. A Schwartze operation had becn performed, but during convalescence the patient fell into the but and the opertion but the granulations were indolert and fetid ischarge continted to appear from the external meatus. Following a milk injection of $1 / 2 \mathrm{c.cm}$. he had a general reaction, but there was a diminuheal rapidly. After the third injection there was no discharge or odour from the middle ear.

These cases are in every way typical of a large number I have successfully treated by the method of milk injec-

* Abstract of a paper read before the Egyptian Branch of the British Medical Association, Norember 14th, 1928. tions. The immediate reaction of patients treated by this method is admittedly unpleasant, but $I$ have no doubt that if its use becomes general there will follow a great reduction in the number of operations performed on the temporal bone. The radical mastoid operation will be resorted to only in cases of cholesteatoma or when intracianial complications are threatened.

\section{SLIPPED EPIPHYSIS OF THE HEAD OF THE FEMUR.}

BY

JOHX J. ROBB, M.C., M.B., F.R.C.S.ED., SLRGEON CONSLLTANT, COLNTY OF ZETLAND.

Coxsiderabe interest has recently ranged around the problem of separation of the ujper epiphysis of the femur, and particularly where the separation has taken place without the aid of tratuma. Such a case recently came under my care, the features of which may be interesting to record.

A boy, aged 14 years, was admitted to hospital as an emergency case. He was in great distress, complaining of severa pain in the left hip-joint. Voluntary movement of the left leg was quite impossible, and even to touch the region of the hip-joint caused him to scream. As the boy lay on his back the thigh was slightly flexed and the foot crerted. Over the greater trochanter there was quite a marked swelling, extremely tender to touch. The generat disturbance was considerable; the boy looked ill; his puls: was 124 and temperature $100.2^{\circ} \mathrm{F}$. An $x$-ray photograph of the hip-joint was takell, and it showed a true separation of the uppir epiphysis of the femur, the head of the bone remaining in the acetabulum, the neck slipping proximally.

The history of this casc prior to coming to hospital is that for some five to six months the boy seemed off colour. His appetito had diminished, and he appeared less energetic than was usual. Five weeks previous to my seeing him he commenced to complain of an aching pain in the left hip-joint, which came and went with the degree of rest he gave it. Occasionally the pain caused him to limp. At midday of the day of admission to hospital he was standing lalking with his brother when something suddenly happened to his left hip-joint which caused him to drop upon the ground. From that moment he was unable to move the limb, and the pain he suffered was extreme. There is a very bad history of tuberculosis in his family. On his mother's side eight out of ten have died from the results of bone and joint tuberculosis.

The next features of interest were noticed during the course of his treatment.

The limb was placed in flexion, abducted by the aid of a Thomas splint, and $15 \mathrm{lb}$. extension applied by means of strapping, ihis following manipulation under a general anaesthetic. Tho result was good, and complete relief from pain was at once obtained. In two dars the temperature and pulse subsided to normal, and at the end of five days the periarticular swelling and tenderness had gone. On the eighth day I measured the limb, and found it to be over-extended by fully half an inch. The weights were therefore reduced to $8 \mathrm{lb}$., and on that same night the pulse and temperature again rose. For three days I allowed the reduced weight exiension to remain, and each day the swing in the pulse and temperature became greater. No pain, however, had returned. At this point the weights were increased to $12 \mathrm{lb}$., with the immediate effect of reducing the pulse and temperature to normal. During the next three weeks this amount of extension was allowed to remain, and no abnormal symptoms of any sort were piesent. To permil of more morement it was then decided 10 reduce the weight extension to $7 \mathrm{lb}$., but again disastrous results followed. The temperature and pulse immediately began to swing. After three dars the $12 \mathrm{lb}$. were reapplied, the result being that symptoms again immediately subsided. Although active and voluntary movement was now encouraged, so long as this extension was maintained everything remained normal.

Two weeks later the extension and splinting were removad. Function was good, and all movements were performed without pain. Only in abduction was there some limitation of movement. In spite of this, however, from the moment extension was removel the pulse and temperature again began to swing-the pulse from 80 in the morning to 110 at night, and the temperature from $98^{\circ}$ in the morning to $100^{C}$ at night. After waiting for one week to sce if these would subside, and failing to get such a result, i was decided to apply a hip plaster in an abducted position. This was done, and in twelve hours everything returned to normal, encl has since remained normal.

The principal features of this case are mentioncd chicfly because of their etiological significance. All history of 
trauma is completely absent, the Wassermann reaction is negative, and, so far as can be ascertained, no endocrine disturbance exists. S. T. Irwin, at a meeting of the Section of Surgery of the Royal Academy of Medicine in Ireland on December 7th, 1928, stated that tubercle was not a causal agent in separation of the upper epiphysis of the femur. In the case described, though it is at present impossible to be dogmatic as to the cause, it seems equally impossible to eliminate the tubercle bacillus as a factor. The strong family tendency to this infection, and the behaviour of the lesion under treatment, are factors too suggestive to be lightly set aside in considering the cause of the condition and its prognosis.

\section{Attentoranda: \\ MEDICAL, SURGICAL, OBSTETRICAL.}

\section{CARCINOMA OF LOWER END OF ILEUM.}

THIs case seems worthy of record for the following reasons: (1) the rarity of carcinoma of the ileum; (2) the difficulty of accurate preoperative diagnosis; (3) the difficulty of deciding the nature of the tumour in the small intestine by the naked eye at the time of operation; (4) tho apparent absence of recurrence following only local excision of the growth and lateral anastomosis.

History.-The patient, a man aged 45 years, was admitted to the Dunfermline and West Fife Hospital on May 3rd, 1926. For six months prior to admission he had been under observation suffering from indigestion and fullness in the epigastrium, worse after food. During this time he had been very constipated, his bowels only acting with purgatives. His general condition was deteriorating, and he had been losing weight steadily. About three months prior to admission he began to complain of pruritus ani. On several occasions he had been treated for " gastritis," but on none of these had he vomited or suffered acute abdominal pain.

Examination.-The patient was spare and in poor condition. His colour was slightly sallow, and his tongue covered with brown fur. His abdomen was slightly distended, and the abdominal muscles were soft and flabby. Palpation on several occasions revealed tenderness on deep pressure over the right iliac fossa, with maximum tenderness over McBurney's point. No thickening was felt in the right iliac region, and there was no epigastrio tenderness. Percussion revealed no abnormality of the liver and spleen. A provisional diagnosis of chronic appendicitis with reflex dyspepsia was made.

Opcration.-On May 4th, 1926, the abdomen was opened through a right rectal incision, displacing the rectus inwards. There was a small amount of free fluid in the abdomen. The appendix, foetal in type, and acutely kinked on itself, was removed. Palpation of the duodenum, liver, and gall-bladder removed. Palpation of the duodenum, liver, and gall-bladder revealed nothing abnormal, but within the terminal portion of
the ileum, about $3 \frac{1}{2}$ in. from the ileo-caecal valve, was felt a round mass about the size of a walnut. The mass was apparently fixed to the posterior wall of the ileum, but there was no dimpling of the' serous coat at the site of attachment. The ileum was opened longitudinally, over the site of the tumour, and a small sessile growth evaginated. The growth was excised locally, and the longitudinal incision on the ileum was closed in the transverse axis of the bowel. The whole ileo-caecal region was turned upwards, and the incision on the posterior aspect of ileum, to which the tumour had been attached, was sutured ileum, to which the tumour had been attached, was sutured
in a similar manner. This suturing narrowed the lumen of the ileum so much that a lateral anastomosis of the lileum to the caecum was made. The after-treatment was uneventful and the patient was discharged on May 14th, 1926.

$\boldsymbol{H}$ istological Examination.-Dr. J. W. Dawson, Royal College of Physicians Laboratory, Edinburgh, reported as follows "Section shows the presence of a diffusely infiltrating smallcelled carcinoma. Further sections show a very marked thickening of serosa and subserosa with tumour cells."

After-History.-On June 4th, 1926, the patient had put on $1 \mathrm{~h}$, in weight, his bowels moving more regularly than they did prior to operation; pruritus ani had disappeared. On $J$ anuary 18th, 19\%/, he was again examined. He was still gaining weight, the abdomen was slightly tumid, the liver was not cnlarged, and there were no abdominal symptoms. $\mathrm{He}$ is now doing full work and has put on 1 st. in weight.

The rarity of carcinoma of the ileum is shown by the following figures from the Encyclopaedia Medica: of 1,148 cases of malignant disease of the intestine (large and small) 26 cases occurred in the ileum. W. J. Mayo, in 1912, reported that of 1,498 operations for carcinoma of the gastro-intestinal tract, only 5 wero for carcinoma of the ileum. The difficulty of diagnosing the condition accurately before operation is well brought out by BlandSutton, who, in Tumours, Innocent and Malignant, writes: "Cancer of the ileum gives rise to no signs which render the localization of the disease a matter of certainty." He also draws attention to the difficulty of deciding the nature of the tumour at the time of operation. In this case the diagnosis of a chronic appendix with reflex drspepsia was made prior to operation, and it was only after the appendix had been removed and the terminal ileum had been palpated that the growth was discovered. At the time of operation there was no evidence of enlarged ileo-caecal or other glands, and the tumour, though sessile and hard; was so well defined that one formed the impression that it was adenomateus. The after-history bears out McK. Craig of Mayo Clinic, who, reviewing 36 cases of cancer of the ileum, wrote that, " although resection of the bowel with associated glands is the operation of choice, yet anastomosis round the lesion results in a high percentage of longevity."

I am indebted to Dr. A. L. S. Tuke for his advice in this case during the operation.

J. M. BlaCK, M.B., Ch.B., F.R.C.S.Ed., Honorary Surgeon, Dunfermline and West Fife Hospital.

\section{PREGNANCY ASSOCIATED WITH DIABETES MELLITUS.}

Wirn reference to the hospital case reported by Dr. Shirley Smith and Mr. Roques in the Journal of January 12th (p. 66) the following details of a case treated in the ordinary course of a country general practice may be of interest.

A panel patient, aged 20, arrived at evening surgery on April 12th, 1927, having walked a distance of about a mile up a steep hill. She looked and complained of feeling acutely ill, and gavo a history of polyuria, constipation, marked thirst, air-hunger, and rapid loss of weight. Up to five days previously she had been carrying on her duties as a domestic servant. She was sent to bed, and a specimen of urine obtained on the following morning was found to be loaded with sugar; the specific gravity was 1038 , and Gerhardt's test was strongly positive

She was put on a diet consisting mainly of boiled cabbage, butter, eggs, and fish, with as little carbohydrate as we could persuade her to take. On April 13th an injection of 20 units of insulin was given with apparently little benefit; this was followed on April 14th by one of 50 units, and on April 15th by 80 units, with marked improvement in the quantity of sugar excreted. On April 16th 95 units was given, wheil the urme became sugar-free and Gerhardt's test negative. For the next became sugar-free and Gerhardt's test negative. For the next
three days she received 60 units daily, but sugar reappeared, and three days she received 60 units daily, but sugar reappeared, and
this was followed by the daily administration of 80 units for five days, which again caused the sugar to disappear. At this stage she was admitted to hospital for examination of the blood sugar content, but insisted on returnng home on the fourth day, before a complete test had been performed. From April 30th she had 60 units of insulin daily, and gained steadily in weight, the sugar being diminished in quantity and occasionally absent. The insulin was gradually reduced, and by October she had gained upwards of a stone in weight and was taking 30 units of insulin daily.

She married in February, 1928, and in August gave birth to an apparently healthy, full-time male infant. The morning sickness was troublesome, but otherwise the pregnancy was uneventful, as was also the labour, which lasted less than twelve hours. During the early part of her pregnancy she had 20 units of insulin daily, but this had to be increased to 45 units towards the end of pregnancy; this dose was continued for eighteen days after delivery, when some mild attacks of hypoglycaemia caused us to reduce it to 30 units daily. She nursed her child, as she had an abundant supply of milk, and continues in excellent health, abundant supply of milk, and continues in excellent health, slight recent loss in weight she has now returned to taking 40 units daily.

This case shows:

1. The successful treatment of a severe diabetic patient in general practice.

2. Agreement with the suggestion of Dr. Shirley Smith and Mr. Roques that the dangers associated with pregnancy and labour in diabetic women no longer exist.

3. Like them we had to increase the amount of insulin during pregnancy.

4. We found no necessity to reduce the amount of insulin until eighteen days after delivery.

5. The successful treatment of this case without the aid of blood sugar estimations.

Chalford, Glos.
M. Grafam Dill, M.D. Alfred V. Dime, M.D., D.P.H. 